\title{
A System Dynamics Simulation Study on the Efficiency of Commercial Banks from the Perspective of Green Credit
}

\author{
Fang CHEN \\ School of Economics, Central South \\ University of Forestry and Technology \\ Changsha, China \\ 11778391@qq.com
}

\author{
Kun ZHANG* \\ School of Business, Central South \\ University of Forestry and Technology \\ Changsha, China \\ Corresponding author: smmff@163.com
}

Li WANG

Bank of Changsha

Changsha, China

71526671@qq.com

Received: December 15, 2019. Revised: Agust 31, 2020. Accepted: October 3, 2020. Published: October 23, 2020.

\begin{abstract}
With the deepened commitment to the green credit policy and increasingly intense competition among commercial banks, the impact of green credit on the efficiency of commercial banks has attracted great attention from the banking industry and governments. To study the efficiency of commercial banks from the perspective of green credit, this paper, with a case study on Bank of Shanghai, builds a system dynamics model to present the causal loop diagram and system flow diagram and seek the functional relations between variables. Then it goes on to simulate the evolution of the policy situation with system dynamics and attempts to find out the change path and evolution direction of green credit and variables regarding bank efficiency when a certain policy is adjusted, with a view to providing theoretical basis and data support for formulation of financial policies and selection of bank strategies.
\end{abstract}

Keywords-Green Credit, Commercial Bank Efficiency, System Dynamics

\section{INTRODUCTION}

As the environmental issue is receiving greater and greater attention, environmental protection, energy saving and emission reduction have become the vital prerequisites for economic development. With the trend of financial globalization and economic structure transformation, green economy and circular economy have gradually become the focuses of economy in China and even the whole world. As is known to all, finance is the core of modern economy. How to give play to the significant role of financial tools without damaging the environment has drawn more and more attention from all walks of life in recent years. Meanwhile, financial institutions have also realized the importance of their social responsibilities. Under such circumstance, green financial policies are being highly valued and green credit has made great strides [1].

With the deepened commitment to the green credit policy and increasingly intense competition among commercial banks, the impact of green credit on the efficiency of commercial banks has attracted great attention from the banking industry and governments. This paper takes the efficiency of commercial banks as its research object, elaborates the basic principles of green credit and the fundamental theories for practice of green credit in commercial banks, and constructs a system dynamics model for selection of green credit strategies by commercial banks and enterprises [2-3].

Our world is a dynamic society permeated with complexity. Usually, we fail to analyze problems from the holistic view and tend to separate the entire structure. As a result, when we try to solve one certain problem, we often ignore the complex system where the problem happens. Many problems that we face are actually a result of our past behaviours, which are unexpected side effects. The construction of a mental model with systematic thinking entails the application of system dynamics methods, as system dynamics helps researchers think systematically, and utilize some tools to understand how the structure of the complex system determines their behaviours. System dynamics is a discipline established by Professor J. W. Forrester of MIT, also known as SD. The approach of system dynamics can assist us in comprehending the structure of complex system and features of dynamic behaviours [4]. In the meantime, it is a precise modelling science that provides standard computer simulation tools for us to figure out complex systems and analyze the internal feedback mechanism and operation structure of such systems.

This paper takes Bank of Shanghai as an example, analyzes the causal feedback process of commercial bank efficiency from the perspective of green credit, captures the impact path and forms a causal loop diagram. Besides, it explores the tempo and level variables in the process of commercial bank operation, builds a system dynamic flow diagram regarding commercial bank efficiency, and simulates the tendency of such efficiency using the system dynamics model [5]. Furthermore, it tests the model results based on historical data so as to verify the reliability of the model, carries out a comprehensive systematic analysis of commercial bank efficiency and investigates the impacts of policy changes on the efficiency by simulating the policy situation evolution using the system dynamics method.

\section{CAUSAL LOOP DiAgRAM}

\section{A. System Framework}

The system boundaries should be determined first, i.e., the scope and extent of the study. Inside the system, differentiated and interactive parts are organically combined by material flow or information flow into a collective to fulfill a certain function for the same purpose. It contains all factors that have major impacts on the features of the system. This paper studies how the green credit of commercial banks increases their efficiency [6]. Given the complex features of the causal relations in economic and financial systems, to work out a system dynamics model for the financial efficiency of commercial banks, the key task is to find a dynamics mechanism, that is, the objective law existing in the evolving process of the system. Through evaluation of the dynamics mechanism, the functions of the financial 
system are summarized. The green credit limit, sunk capital and bank profit form the major causal loop [7].

\section{B. Causal Feedback Relationship}

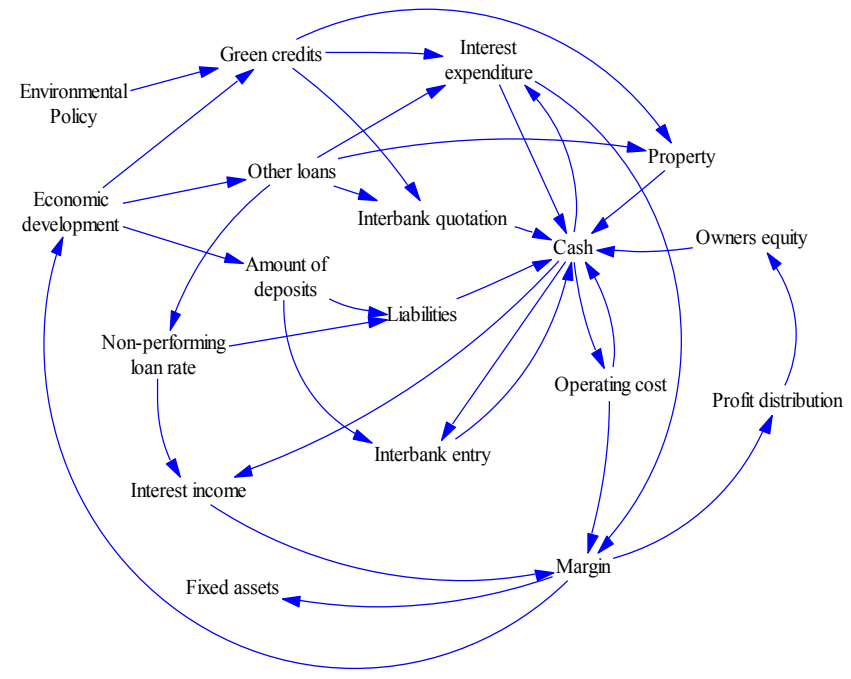

Fig. 1. Causal Loop Diagram

In the theoretical model of system dynamics, the actions of factors are all established through certain links, which constitute the causal relationship. It is such relationship that eventually determines the functions and behaviours of a system [8]. Hence, causal relationship analysis should be conducted before the system dynamics model is constructed. Causal relationship analysis is an approach of describing the internal structure relations of a system on a qualitative basis, and the causal relations between factor variables inside such system are called causal chains. The causal loop diagram is a chart that reflects the causal relationship [9-10], where the relationship is commonly expressed by arrows. For instance, $\mathrm{A} \rightarrow \mathrm{B}$ suggests a causal relationship between variable $\mathrm{A}$ and variable $B$ in which variable $A$ is the cause while variable $B$ is the result. The causal loop diagram serves as an important tool to demonstrate the feedback system structure. Its main purpose is to quickly work out a hypothesis on causes of the system. It includes multiple variables connected by arrows to indicate causal relations [11-13]. This paper depicts the causal loop of the system according to the variables of the green credit system of commercial banks, which is shown in Fig. 1.

\section{COnstruction OF System DynAmics Model}

\section{A. System Flow Diagram}

To further learn about the relations between different variables through systematic analysis, we need to study the functions or quantitative relations between them and determine their functional equations. However, first, we need to establish a systematic causal loop diagram and a system flow diagram, as they are the qualitative description of a system's internal structure, functions and interactions. The system flow diagram should contain causal chains of all influencing factors and corresponding data. By doing so, we can explicitly grasp the factor variables of the system model. Moreover, we can have a better knowledge of the functional equations between variables and the corresponding system parameters and constants of the system. See the system flow diagram in Fig. 2.

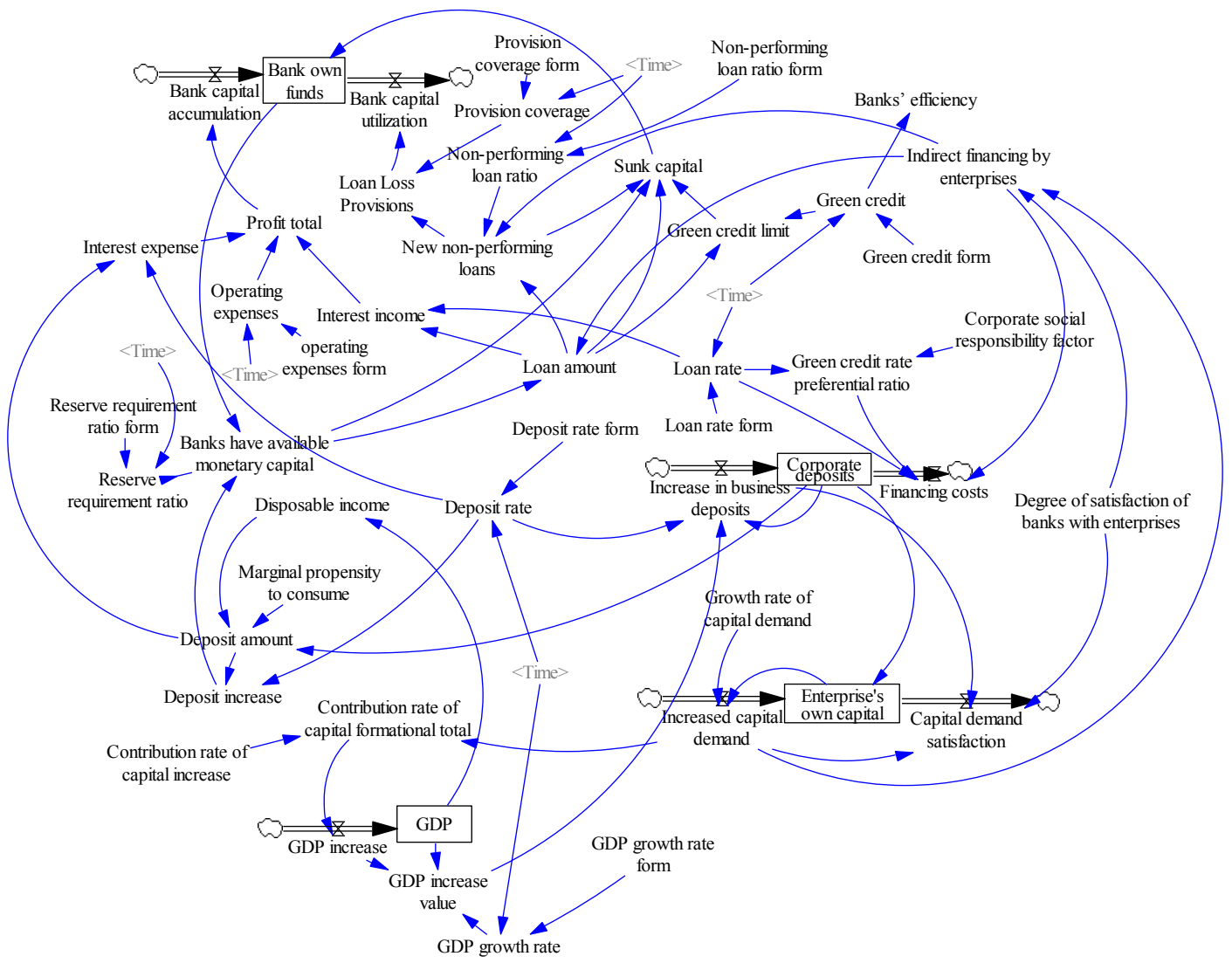

Fig. 2. System Flow Diagram 


\section{B. Description of Variables}

Variables employed in the system flow diagram are selected on the logical basis of the causal loop diagram, including status variable, tempo variable, auxiliary variables (including table functions) and constants. These variables are not completely identical with those in the causal loop diagram because arrows in the causal loop diagram represent causal relations between variables while those in the flow diagram indicate material flow and information flow. Considering the capacity of the model and to simplify analysis, this paper uses data from the Annual Reports of Bank of Shanghai, Corporate Social Responsibility Reports, China Financial Statistics Yearbooks and Annual Reports of China Banking Regulatory Commission, etc [14-16]. from 2005 to 2015. This paper adopts green credit limit, sunk capital and total profits as the endogenous variables to examine the changes in the efficiency of a commercial bank. The equations of variables and some data in the model refer to the empirical findings of Section 4 , and some parameters are based on related literatures and historical experience. Regression analysis is also conducted on the variables to obtain the relation equations between different variables when their functional relations cannot be confirmed in a graphic manner. The unit used in this paper is billion and the time step is 1 . Parameters of all causal factors are embedded in the model [17]:

\section{INITIAL TIME $=2005$}

FINAL TIME=2015

\section{SAVEPER=TIME STEP}

\section{TIME STEP $=1$}

Key endogenous variables which describe the bank efficiency are sunk capital and green credit limit [18].

\section{(1) Sunk Capital}

Sunk capital can occur in any department or step of capital operation. The capital of the corporate sector which does not flow to entity economy and the equity capital of the bank after deduction of the statutory reserves collected by the central bank will constitute the available monetary capital of the bank. The sum of such monetary capital minus the loans (excluding new non-performing loans) is the sunk capital of the bank. See Fig. 3 for the sunk capital causal tree of the system flow diagram.

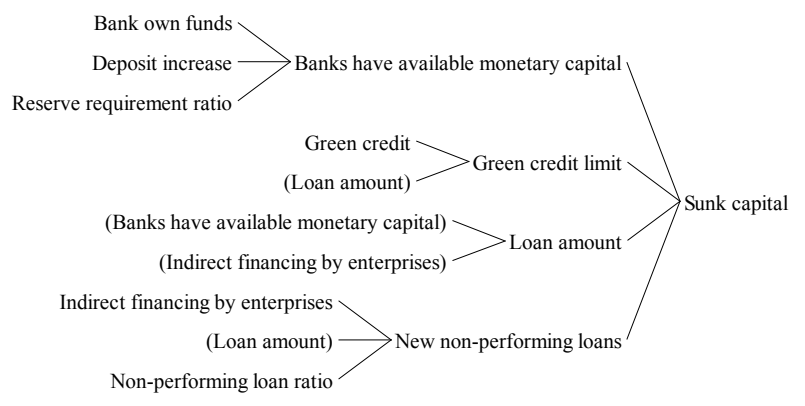

Fig. 3. Sunk Capital Causal Tree

\section{(2) Green Credit Limit}

The green credit limit of a commercial bank is jointly determined by the green credit ratio and the total loans. See
Fig. 4 for the green credit causal tree of the system flow diagram.

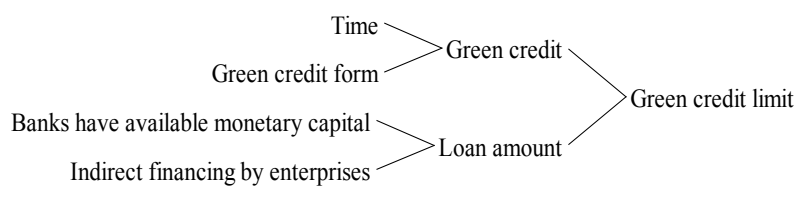

Fig. 4. Green Credit Causal Tree

\section{Model Verification AND Policy Simulation}

\section{A. Model Verification and Operation}

The initial values and constants of the model equation can be determined through expert assessment and regression analysis of historical data. Experts can be invited to give scores pursuant to actual conditions of the factor variables and then simulation can be conducted. If the simulation results are not ideal, another simulation should be conducted with the values of related factor variables adjusted until the effect is satisfactory. Before simulation, collected data should be quantified and processed, and for those that are not easy to process, the initial values can be decided through expert assessment [19].

(1) Dynamics test. The boundary, types of variables, definitions, causal relations and system equations can be directly verified against the modelling purpose and based on professional knowledge and grasp of system dynamics. Excessively rough division of boundaries may lead to ignorance of important variables and feedback chains, while excessively fine division may result in huge research workload in terms of system equations, and make the main causal relations between system behaviours more ambiguous.

(2) Operation test. When the Vensim software is used for simulation, the detection function of the software will advise the structure error and equation error of the model as well as the rationality of system parameters. In the test, there was an alert about an error of the simultaneous equations after the model started operation, and some variables did not show up in the equation. Through examination and reconsideration of the causal loop, the model was operated again, and this time there was no alert. In the end, the model result was close to the reasonable level after repeated modification.

(3) Stability test. To examine the stability of the model, the software was used to compare the simulation curves at different time steps, which were respectively a year, half a year and a quarter. The three curves basically overlap, which means the model is stable.

\section{B. Situation Evolution Simulation}

The situation evolution simulation is designed to learn about the possible tendencies of related key variables when changes take place in these variables. To investigate the influences of green credit changes over commercial bank efficiency, this section compares and analyzes the simulation results, as shown in Fig. 5. Current11 indicates that the green credit limit is raised by $20 \%$ while Current means that the green credit limit remains the same. According to simulation results, bank efficiency has been significantly enhanced. Green credit and bank efficiency are in a positive feedback 
relationship. Green credit exerts positive influences over the intermediate business, credit structure, international competitiveness and reputation of the commercial bank and thus improves its efficiency.

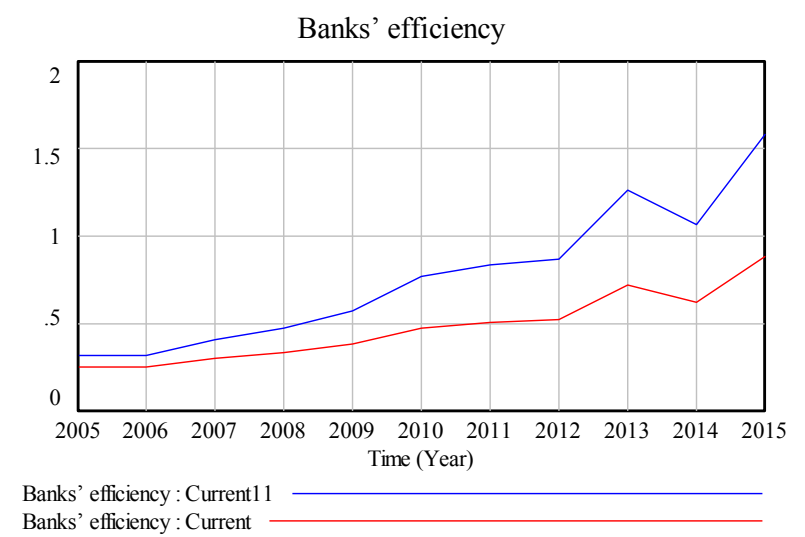

Fig. 5. Simulation Results of Bank Efficiency

\section{CONCLUSION}

This paper conducts a system dynamics simulation study on the financial efficiency of commercial banks based on the data of Bank of Shanghai. First of all, it selects the main variables that influence the financial efficiency of commercial banks to carry out system simulation in two modules - enterprises and banks. Afterwards, it establishes a causal loop diagram through the causal feedback relations of variables. It also employs regression analysis to obtain the functional relations of some variables using data from 2005 to 2015. Then this paper determines correlation coefficients and construct equations based on the correlations of different variables. After that, it imports the obtained equations respectively to the Vensim software model to establish the flow diagram. Meanwhile, it adjusts the parameters and coefficient relations repeatedly to verify the boundary of the model. Through the history test and the stability test, the model proves to have satisfying effectiveness and truly reflect the financial efficiency of a commercial bank. On this basis, this paper further explores the impacts of green credit on commercial banks, and proposes related policy suggestions. In the future, the Chinese government should make great efforts to establish a sound multi-level green standard system, improve the green information release mechanism and strengthen its policy support and guidance. These efforts will create a favourable policy environment and standard market order for the promotion of green credit, and boost the on-going enhancement of technological innovation efficiency. In the meantime, commercial banks should improve their own management level and make use of the market forces to increase their operation efficiency [20-22].

\section{ACKNOWLEDGMENT}

This work was supported by The Ministry of education of Humanities and Social Science project of China under the Project No. 15YJCZH010; and Hunan Provincial Education Science 13th Five-year Planning Project No. XJK17QGD018; and "Research on Optimizing Mechanism of Metal Resources Industrial Structure in Hunan Province by Supply-side Structural Reform", Youth Fund key Projects of Central South University of Forestry and Technology, 2016.

\section{REFERENCES}

[1] K. Q. Li, "A Number of Issues regarding Adjustment of Economic Structure to Promote Sustainable Development," Qiushi, no. 6, 2010.

[2] X. C. Zhou, "On Supporting Energy Saving and Emission Reduction through Financial Market," China Financialyst, no. 8, 2007.

[3] X. X. Li, G. Xia, "China Green Finance Report 2014," China Financial Publishing House, 2004.

[4] X. J. Wang, "How to Develop Green Credits of Commercial Banks," Reformation \& Strategy, no. 5, 2012, pp. 80-83.

[5] B. Hui, "A Study on Support of Green Finance for Circular Economy," Tianjin: Tianjin University of Finance and Economics, 2012.

[6] J. P. Liu, "Green Management and China's Financial Industry Development," Master's Thesis of Hefei University of Technology, 2004.

[7] D. X. He, X. L. Zhang, "Thoughts on a Number of Issues regarding Promotion of Green Credit in China's Commercial Banks," Shanghai Finance, vol. 12, 2007, pp.4-9.

[8] Y. T. Yin, “A Study on Influences of Green Credit over Commercial Banks' Profitability," Nanjing Normal University, 2015.

[9] R. Chen, "A Study on the Relationship between Green Credit and Sustainable Development of Commercial Banks," Hunan University, 2014.

[10] Y. Y. Wu, "Exploration of Green Credit Mechanism Construction from the Perspective of Financial Crisis," Journal of Finance and Economics, no. 7, 2009, pp. 38-40.

[11] N. K. Avkiran, "Association of DEA super-efficiency estimates with financial ratios: Investigating the case for Chinese banks," Omega, vol. 39 , no. 3, 2011, pp. 323-334.

[12] C. P. Barros, Z. Chen, Q. B. Liang, "Technical efficiency in the Chinese banking sector," Economic Modelling, vol. 28, no. 5, 2011, pp. 2083-2089.

[13] M. Asmild, K. Matthews, "Multi-directional efficiency analysis of efficiency patterns in Chinese banks 1997-2008," European Journal of Operational Research, vol. 219, no. 2, 2012, pp. 434-441.

[14] K. Matthews, "Risk management and managerial efficiency in Chinese banks: A network DEA framework," Omega, vol. 41, no. 2, 2013, pp. 207-215.

[15] H. Yin, J. Yang, J. Mehran, "An empirical study of bank efficiency in China after WTO accession," Global Finance Journal, vol. 24, no. 2, 2013, pp. 153-170.

[16] C. Jiang, S. Yao, G. Feng, "Bank ownership, privatization, and performance: Evidence from a transition country," Journal of Banking \& Finance, vol. 37, no. 9, 2013, pp. 3364-3372.

[17] P. Pessarossi, L. Weill, "Do capital requirements affect bank efficiency?" Evidence from China, 2013.

[18] Z. Fungáčová, P. Pessarossi, L. Weill, "Is bank competition detrimental to efficiency? Evidence from China," China Economic Review, vol. 27, 2013, pp. 121-134.

[19] X. G. Chen, M. Skully, K. Brown, "Banking efficiency in China: Application of DEA to pre-and post-deregulation eras: 1993-2000," China Economic Review, vol. 16, no. 3, 2005, pp. 229-245.

[20] M. Ariff, C. Luc, "Cost and profit efficiency of Chinese banks: A non-parametric analysis," China Economic Review, vol. 19, no. 2, 2008, pp. 260-273.

[21] A.D. Angelis, L. Ceccotti, O. Saro, "Energy savings evaluation for dry-cooler equipped plants in shopping mall buildings," International Journal of Heat and Technology, Vol. 35, Special Issue 1, 2017, pp. S361-S366.

[22] S.L. Song, "Application of gray prediction and linear programming model in economic management," Mathematical Modelling of Engineering Problems, Vol. 5, No. 1, 2018, pp. 46-50.

Creative Commons Attribution License 4.0 (Attribution 4.0 International, CC BY 4.0)

This article is published under the terms of the Creative Commons Attribution License 4.0 https://creativecommons.org/licenses/by/4.0/deed.en_US 